\title{
A FORMAÇÃO CENTRADA NA ESCOLA: MEDIAÇÃO PARA A ORGANIZAÇÃO DO TRABALHO PEDAGÓGICO
}

\author{
THE SCHOOL-CENTERED TRAINING: \\ MEDIATION FOR THE ORGANIZATION OF PEDAGOGICAL WORK
}

\begin{abstract}
Ademar de Lima Carvalho
Professor titular I do Programa de Pós-graduação (PPGEdu) e do Departamento de Educação da Universidade Federal de Rondonópolis (UFR), Rondonópolis, Mato Grosso, Brasil. Mestre e doutor em Educação. ademarlc@terra.com.br

Izelda Goreth dos Santos Mangialardo

Professora da rede pública municipal de ensino de Rondonópolis, Mato Grosso, Brasil. Mestra em Educação pela Universidade Federal de Mato Grosso, campus Rondonópolis. izeldgoreth@hotmail.com

Resumo: Este artigo apresenta uma reflexão teórica sobre a formação centrada na escola como instrumento para a organização do trabalho pedagógico. Ancora-se em alguns teóricos que contribuíram para elucidar a questão, dentre eles, destacamos: Freire (1991; 1997; 2001; 2011; 2015), Carvalho (2005; 2006; 2010), Veiga (1995), Ferreira (2008), Domingues (2014), Imbernón (2009). O estudo fundamentase na perspectiva de uma formação onde há interação, diálogo, reflexão, participação e avaliação entre os atores envolvidos no âmbito escolar para que possam ser criadas alternativas para melhoria da prática educativa. $\mathrm{O}$ ato da reflexão da prática impulsiona o professor à busca investigativa como possibilidade de transformação e inovação da prática pedagógica. A formação centrada na escola toma como ponto de partida as situações problemáticas que desafiam a prática do professor no processo em que se organiza o trabalho pedagógico e o levam a assumir-se como sujeito da ação comprometido com sua transformação.
\end{abstract}

Palavras-chave: Educação. Formação centrada na escola. Professor. Trabalho pedagógico.

\begin{abstract}
This article presents a theoretical reflection on school-centered training as an instrument for organizing pedagogical work. It is anchored in some theorists who contributed to elucidate the issue, among them, we emphasize: Freire $(1991 ; 1997 ; 2001 ; 2011 ; 2015)$, Carvalho $(2005 ; 2006 ; 2010)$, Veiga (1995), Ferreira (2008), Domingues (2014), Imbernón (2009). The study is based on the perspective of training where there is interaction, dialogue, reflection, participation and evaluation between the individuals involved in the school environment, so that alternatives can be created to improve educational practice. The act of reflecting on the practice impels the teacher to the investigative search as a possibility of transformation and innovation of the pedagogical practice. School-centered training takes, as a starting point, problematic situations that challenge the teacher's practice in the process in which the pedagogical work is organized and lead him to assume himself as the subject of the action, committed to his own transformation.
\end{abstract}

Keywords: Education. School-centered training. Teacher. Pedagogical work.

Para citar - (ABNT NBR 6023:2018)

CARVALHO, Ademar de Lima; MANGIALARDO, Izelda Goreth dos Santos. A formação centrada na escola: mediação para a organização do trabalho pedagógico. Eccos - Revista Cientifica, São Paulo, n. 55, p. 1-16, e8389, out./dez. 2020. Disponível em: https://doi.org/10.5585/eccos.n55.8389. 


\section{Introdução}

O que propomos, com o presente estudo, é apresentar uma reflexão sobre a formação centrada na escola como pressuposto para problematizar a prática docente, visando uma compreensão do processo de organização do trabalho pedagógico. A discussão se deu a partir do entendimento de que na escola acontecem os desafios e se desenham os limites e possibilidades, sempre com o propósito de pensar uma alternativa para a educação de qualidade social.

Em nossa realidade, a escola tem sido problematizada quanto à questão da qualidade do ensino e formação dos professores - inicial e contínua - tendo em vista que é de competência do professor construir os saberes necessários à prática docente (GADOTTI, 2007).

Partindo do entendimento de que o professor é sujeito de seu ato pedagógico no processo de ensino e aprendizagem, a questão levantada, desde o início da reflexão, para pensar a qualidade da educação, do ensino e da docência, é: qualidade para quem? Essa questão faz com que pensemos na importância da formação permanente do professor e sua inter-relação com a organização do trabalho pedagógico na escola. Da mesma forma que destacamos que "educar é sempre impregnar de sentido todos os atos da nossa vida cotidiana" (GADOTTI, 2007, p. 42), compreendemos que, em se tratando do trabalho pedagógico na escola, é fundamental pensar nos sujeitos envolvidos na práxis educativa, que são os professores, coordenador e diretor e, de modo especial, os alunos.

No exercício da prática docente, o professor encontra desafios que precisam de elucidação para permitir a tomada de decisão, por isso que a reflexão sobre a qualidade da educação possibilita entender que a educação é um ato de decisão política. A escola se configura como espaço de encontro com pessoas, seres pensantes, seres humanos. Portanto, neste ponto é "que compreendemos que refletir sobre a qualidade da educação significa refletir sobre a razão do ser humano, pessoa, gente enquanto sujeito da produção e transformação do mundo." (CARVALHO, 2010, p. 20).

Partindo do pressuposto de que a escola é, como pondera Freire (1991, p. 16), uma organização política "não só um espaço físico. É um clima de trabalho, uma postura, um modo de ser", o professor precisa refletir acerca de como ele próprio deve ser para ensinar, definir seus objetivos e perseguir os seus sonhos, pois, para realizá-los, é necessário buscar, mobilizarse, e não um cruzar de braços esperando que as coisas aconteçam.

Porém, para que a tomada de decisão frente aos desafios que perpassam a prática pedagógica se concretize, é importante problematizar a desigualdade social que interfere na 
ação docente na sala de aula. Para ampliar a reflexão, Gallert (2016, p. 41) destaca que "esse cenário de desafios do contexto escolar encontra-se intimamente relacionado com a conjuntura social que vivemos, que adentra a escola e constitui a maneira como as situações são vividas entre as pessoas".

Pensamos que a transformação da prática educativa ocorre a partir da inquietação, dos conflitos que requerem uma mudança. E na escola, para que haja transformação e seja alcançada a qualidade pretendida, é primordial uma postura investigativa que gere conhecimento, para, assim, ser possível compreender a ação organizativa da escola, que se configura na organização do trabalho pedagógico, a qual implica na prática pedagógica desenvolvida no espaço da sala de aula. Brandão (2014, p. 19) argumenta que "talvez o maior desafio de nosso tempo seja o de aprender a compreender que a educação está sempre podendo tomar um rumo ou outro". Neste texto, a nossa reflexão aponta para o rumo da educação que busca formar pessoas, sujeitos conscientes, capazes de, criativamente, transformar a realidade em que estão inseridos.

Nessa perspectiva, a organização do trabalho pedagógico se dá por meio de planejamento, construção do Projeto Político Pedagógico, de uma forma democrática, que envolve a participação da comunidade educativa no processo de tomada de decisão do rumo, do caminho que a escola deve seguir. Tendo em vista que a participação coletiva dos envolvidos é necessária, compreendemos que é no espaço investigativo-formativo permanente que os professores podem construir um novo olhar para a prática. Entendemos que é o estudo que propiciará uma melhor qualidade da análise do processo organizativo da ação pedagógica do professor, num processo de formação que é um instrumento imprescindível para a qualidade da educação.

Freire (2001) enfatiza que:

A melhora da qualidade da educação implica a formação permanente dos educadores. E a formação permanente se funda na prática de analisar a prática. É pensando sua prática, naturalmente com a presença de pessoal altamente qualificado, que é possível perceber embutida na prática uma teoria não percebida ainda, pouco percebida ou já percebida, mas pouco assumida. (FREIRE, 2001, p. 37).

A luta pela educação é fundamental, mas, para que ela se efetive, é preciso tanto o engajamento de todos como o reconhecimento do direito de voz e autonomia dos atores envolvidos no processo educacional. É essencial, também, ter clareza de que a "a autonomia da escola não implica dever o Estado fugir a seu dever de oferecer educação de qualidade e em quantidade suficiente para atender a demanda social.” (FREIRE, 2001, p. 39), isto é, não se pode descartar a ideia de que o Estado cumpra com o seu dever no que tange à educação. 


\section{A formação centrada na escola e os saberes pedagógicos}

Hoje, diante dos desafios que os professores encontram para ensinar no contexto da escola pública, é indispensável que continuemos investindo na formação docente visando uma educação de qualidade. Da mesma forma que é importante o engajamento político na luta pela transformação e mudança na perspectiva de uma educação para a justiça social, pensamos que "uma das condições necessárias para que nos tornemos um intelectual que não teme a mudança é a percepção e a aceitação de que não há vida na imobilidade. De que não há progresso na estagnação.” (FREIRE, 2001, p. 43). Nesse sentido, compreendemos, como Freire (2001), que não podemos ficar no comodismo, estagnados, sem nos mobilizarmos, porque "não adianta almejar mudanças e transformações maiores, se não se inicia por mudar e transformar os espaços de que se dispõe." (LIMA, 2007, p. 112).

Por isso, enfatizamos a necessidade de sermos compromissados e responsáveis, social e politicamente, por nossos saberes pedagógicos. No que se refere à questão sobre os saberes pedagógicos, Franco (2008) assevera que:

[...] os saberes pedagógicos são possíveis em um sujeito que vai gradativamente assumindo uma posição política frente ao compromisso de ser professor, engajandose criticamente em suas circunstâncias, cercando e acercando-se de sua realidade existencial, transformando-a em direção às suas intencionalidades. Assim assumido, esse sujeito vai fazer uso do necessário conhecimento didático, metodológico, cultural, servindo-se desse aparato teórico-prático, para ir construindo em ação seus saberes disciplinares, didáticos metodológicos. A capacidade de articular o aparato teórico-prático, a capacidade de mobilizá-lo na condição presente, a capacidade de organizar novos saberes a partir da prática, essas capacidades em conjunto, estruturam aquilo que chamo de saberes pedagógicos. (FRANCO, 2008, p. 135).

Porém, para proceder no aprofundamento sobre a questão do pedagógico, faz-se necessário compreender a diferença entre saberes pedagógicos e conhecimentos pedagógicos. Para elucidar tal distinção, Franco (2008) declara:

Considero que os saberes pedagógicos são construções cognitivas, realizadas pelos professores, a partir de sua prática cotidiana, que é significada, inicialmente, por conhecimentos pedagógicos prévios, que se organizam sob forma de concepções e pressupostos, sobre os sentidos de ser e de estar professor.

Os conhecimentos pedagógicos são construções teóricas, elaboradas por pesquisadores da área, que se organizam sob forma de teorias ou preceitos e que são apropriados pelos docentes, quer sob a forma de estudos ou pesquisa, quer sob a forma de generalizações teóricas do senso comum. (FRANCO, 2008, p. 136, grifo nosso).

Considerando que os termos saberes pedagógicos e conhecimentos pedagógicos possuem conceitos diferentes, convém refletir para que não haja uma dicotomia entre teoria e prática, tendo em vista a impossibilidade de teoria sem prática, como também, prática sem teoria. Todavia, é preciso ressaltar que, no contexto da escola, a prática pedagógica fragmentada é ainda perceptível, sobretudo no que diz respeito à "organização do processo de trabalho 
preconizada pelo plano de desenvolvimento da escola é segmentada e fragmentada; os professores trabalham isoladamente, dicotomizando as relações teoria-prática.” (VEIGA, 2012, p. 53). Por isso que a formação permanente dos professores se torna tão necessária, como processo de reflexão crítica sobre a organização do trabalho pedagógico na escola.

Ante o exposto, pensamos que a dissociação entre teoria e prática pode vir a dificultar a organização do trabalho pedagógico no espaço educativo. É comum ouvir, no cotidiano escolar, os docentes afirmarem que teoria não resolve o problema da educação e que a experiência, a prática, é o que prevalece quando se trata de atuar profissionalmente.

Embora sejam importantes, a experiência e a reflexão da prática, até porque é dela que se extrai a teoria, também vemos que "a teoria como cultura objetivada é importante na formação docente, uma vez que, além de seu poder formativo, dota os sujeitos de pontos de vista variados para uma ação contextualizada." (PIMENTA, 2002, p. 26). Nesse sentido, salientamos a fundamental importância da relação entre teoria e prática.

Ainda de acordo com Pimenta (2002),

Os saberes teóricos propositivos se articulam, pois, aos saberes da prática, ao mesmo tempo ressignificando-os e sendo por eles ressignificados. O papel da teoria é oferecer aos professores perspectivas de análise para compreenderem os contextos históricos, sociais, culturais, organizacionais e de si mesmos como profissionais, nos quais se dá sua atividade docente, para neles intervir, transformando-os. (PIMENTA, 2002, p. 26).

A superação da dicotomização entre teoria e prática permite um melhor desenvolvimento do trabalho docente, tendo em vista que a "dialeticidade entre teoria e prática deve ser plenamente vivida nos contextos teóricos da formação" (FREIRE, 1997, p. 71). A formação continuada dos professores, a qual propicia a reflexão crítica da e na prática, se constitui nesse movimento dialético entre teoria e prática, como defende Freire (1997).

No entanto, é fundamental que se efetive uma política de formação permanente na escola, que possibilite que os educadores envolvidos no processo educativo possam refletir sobre suas práticas, a fim de que planejem e elaborem suas propostas curriculares sem que sejam escravos dos "pacotes" feitos pelos "experts”. Sendo assim, é necessário e urgente que a escola se organize e lidere seus trabalhos democraticamente, "entendendo que democracia não se confunde com escolher, eleger, pessoas ou governantes, mas ter a possibilidade de construir um projeto político com liberdade" (GADOTTI, 2007, p. 51). Trabalhar de forma democrática promove a participação de todos nos planos, nos projetos, nas ações do cotidiano escolar.

Na perspectiva da educação cidadã, Freitas (2004) mobiliza para o engajamento em 
[...] defesa de uma concepção libertadora da educação que oriente a reinvenção da escola na perspectiva de sua gestão democrática, justifica-se por ser este um caminho para a constituição de práticas sociais que, tanto quanto são produtos de um processo de conscientização, são também produtoras de condições favoráveis ao seu desenvolvimento. (FREITAS, 2004, p. 157).

A ação de desenvolver o trabalho educativo de forma democrática, garantindo efetivamente a participação de todos nas ações escolares, possibilita a mobilização da atividade de ensino e aprendizagem de melhor qualidade, porque professores e alunos assumem, nesse processo, a condição de sujeito. Desse modo, para o desenvolvimento da ação pedagógica no cotidiano da escola, sobretudo no espaço da sala de aula, o professor precisa entender que é fundamental o trabalho coletivo, a pesquisa como suporte para o pedagógico e, ao mesmo tempo, mediação e espaço formativo. Nesse aspecto, compreendemos que, para ensinar, o professor, além de possuir experiência, tem que estudar para reinventar, recriar e reescrever a organização do trabalho pedagógico na escola.

Partindo do pressuposto de que para ensinar o professor necessita tanto de liberdade pedagógica como de uma participação ativa no processo de decisão do projeto educativo da escola, entendemos que a formação permanente é condição para a reinvenção da organização do trabalho pedagógico na perspectiva do exercício da democracia no contexto da escola. Aqui, a escola democrática está sendo referenciada ao pensamento de Lück (2009, p. 69), que a define como "aquela em que os seus participantes estão coletivamente organizados e compromissados com a promoção de educação de qualidade para todos".

Na perspectiva de educação de qualidade, todos os envolvidos trabalham pelos objetivos comuns. A qualidade pretendida se dá a partir da consciência crítica e consequente reflexão sobre o cotidiano escolar em busca de ações transformadoras para "ajudar o mundo a se transformar" a fim de se tornar um mundo melhor para todas as pessoas. Promover mudanças requer pensar o presente, bem como "comprometimento individual em função de um projeto coletivo" e conscientização como método de formação no processo da "construção do ato enquanto prática social” (FREITAS, 2004, p. 158).

Diante dessa realidade, que desafia a prática pedagógica, é fundamental reconhecermos nosso inacabamento, incompletude, porque estamos em constante construção. Pensamos como Freire $(2015$, p. 50), que “o inacabamento do ser ou sua inconclusão é próprio da experiência vital. Onde há vida, há inacabamento. Mas só entre mulheres e homens o inacabamento se tornou consciente". É com essa consciência de nosso inacabamento que adentramos no movimento contínuo de luta na esperança de resistir aos obstáculos do cotidiano escolar e, assim, aprender e ensinar com qualidade. 
Concordamos com Carvalho (2005), quando afirma que educação de qualidade:

[...] é a que propicia espaço, condições para a formação de sujeitos históricos capazes de, conscientemente, produzir e transformar a sua existência. A qualidade da escola tem relação direta com os conteúdos transmitidos e assimilados, com compromisso, com a solidariedade de classe, com a forma como utiliza o universo escolar no sentido da elaboração da cultura, como desenvolve na ação pedagógica a tarefa de pensar, organizar e como coloca em prática o programa de formação de professores. (CARVALHO, 2005, p. 228).

Compreendemos, como o autor, que pensar em educação de qualidade implica várias questões no cotidiano escolar, e, portanto, é preciso que haja conscientização para que possamos problematizar e assumirmos um papel enquanto sujeitos do conhecimento, pois "a conscientização é elemento central da concepção libertadora da educação, uma vez que o ato de conhecimento, nesta perspectiva, implica uma aproximação crítica da realidade" (FREITAS, 2004, p. 150). A conscientização defendida por Freitas (2004) constitui-se numa leitura crítica da realidade. É o conhecimento dessa realidade que provoca uma ação transformadora.

É importante pensarmos em uma consciência crítica, a qual "vê o mundo de forma dinâmica; o tempo não é mais repetitivo e o homem não se contenta em ser mero espectador da história da vida; percebendo-se capaz de transformar a realidade e também a si mesmo" (FREITAS, 2004, p. 153). Dessa maneira, a consciência crítica supera a consciência ingênua, que é totalmente contrária, por não ser dinâmica e ter caráter estático.

Tomando por base a conscientização como elemento central da concepção libertadora de educação, como defende Freitas (2004), percebemos a necessidade de uma ação transformadora da realidade, pois é a partir da conscientização que o sujeito se faz e refaz a si próprio, numa luta constante contra qualquer tipo de obstáculos, na esperança de um futuro mais dinâmico, mutável e humano. Adotando esse raciocínio, acreditamos que os atores envolvidos no processo escolar possam refletir sobre suas ações na cotidianidade. Como vemos, é um desafio tornar-se um professor libertador, "que convida os alunos para a transformação, que ensina de modo dialógico, e não de modo autoritário, que dá o exemplo como estudioso crítico da sociedade" (FREIRE, 2011, p. 222). Logo, é necessário romper com a educação bancária, repudiada por Freire, considerando essa educação como depósitos de informações feitos a alunos tidos como passivos, recipientes vazios e meros receptores. Nessa educação bancária, a relação entre professor e aluno é vertical, há transferência de informações do professor que sabe ao aluno que não sabe, é uma relação totalmente antidialógica. Nesse sentido, é vital pensar numa educação libertadora, problematizadora, dialógica, humana, em que o aluno é ativo, crítico e criativo. 
É nessa vertente que defendemos a formação como elemento fundamental para o professor refletir sobre sua prática e organizar seu trabalho pedagógico. Nessa ótica, “o professor reflexivo seria aquele que adota uma pedagogia pautada no saber escolar e concentra sua ação nas 'representações configurativas' contidas no conhecimento-na-ação dos alunos (o conhecimento cotidiano, tácito)" (DUARTE, 2010, p. 28, grifo do autor).

A formação é vista como um fator imprescindível e resolutivo de mudança na educação. Neste aspecto, cremos que a mudança se dá pela inquietação e curiosidade, assim como pela busca de ser mais: mais humanizados, conscientes e mais felizes. A escola tem um papel significativo nesse processo formativo, uma vez que se torna, para os atores envolvidos, espaço de discussão, de pensar e repensar suas ações para a organização de seu trabalho pedagógico.

Explica Carvalho (2006) que:

[...] a escola é, ao mesmo tempo, espaço de transmissão, produção do conhecimento e orientação educativa. E o próprio projeto político pedagógico, enquanto plano de orientação para a prática, configura como eixo nuclear para a interação recíproca das pessoas que compõem a comunidade escolar. E o exercício de construção do projeto e de problematização da prática é que impulsiona o professor à necessidade de estudo, de buscar respostas pedagógicas aos desafios colocados pela ação pedagógica. (CARVALHO, 2006, p. 181).

Assim como o supracitado autor, acreditamos que a formação dos professores se firmará significativamente se agregada ao processo de organização da escola. Por isso, é necessário que a formação na escola esteja articulada ao projeto político pedagógico. É nesse projeto que constam nossas intenções, o que queremos realizar no cotidiano escolar, como pondera Veiga (1995). Para essa mesma autora, o Projeto Político Pedagógico

[...] vai além de um simples agrupamento de planos de ensino e de atividades diversas. O projeto não é algo que é construído e em seguida arquivado ou encaminhado às autoridades educacionais como prova de cumprimento de tarefas burocráticas. Ele é construído e vivenciado em todos os momentos, por todos os envolvidos com o processo educativo da escola. (VEIGA, 1995, p. 12-13).

No que concerne ao projeto político pedagógico, defendemos, como Veiga (1995), que este vai além de um plano de ensino e atividades. A autora expõe que o projeto não é algo construído e sequencialmente arquivado. Entretanto, o que acontece nas escolas é exatamente isso, o projeto, muitas vezes, é construído e revisado sem contar com a participação efetiva de todos. Essa não participação se deve à não disponibilidade de tempo e por acontecer na semana pedagógica (antes do início do ano letivo), período em que ainda não há a concretização do quadro de professores, para que pudessem contribuir efetivamente nas discussões e na tomada de decisão. Assim, mesmo tendo sido revisado pela minoria, o projeto é encaminhado às autoridades educacionais, como também, há seu arquivamento. Na contramão dessa realidade, é necessário que as escolas tomem consciência de sua importância e que o projeto não sirva 
somente para cumprimento de tarefas às autoridades, simplesmente para justificar que a escola “tem” um Projeto Político Pedagógico.

Para isso, é indispensável que todos os atores do âmbito escolar estejam envolvidos na construção e/ou revisão do projeto político pedagógico, uma vez que "o projeto mostra um rumo, uma direção. É uma ação intencional com um sentido explícito, com um compromisso definido coletivamente" (VEIGA, 1995, p. 13). É o momento de ouvir a todos, seus interesses, suas intenções, as problemáticas vivenciadas no cotidiano escolar.

Vemos, então, a necessidade de construir o projeto político pedagógico de forma coletiva nas escolas, para que possam organizar o trabalho pedagógico. A reflexão sobre essa questão se fundamenta no pensamento de Ferreira (2008), que elenca alguns aspectos norteadores para a organização do projeto político pedagógico de uma escola, para que, posteriormente, seja organizado o trabalho pedagógico:

Todo projeto pedagógico é Projeto Político-pedagógico, na medida em que não se faz senão contextualizado a partir do diagnóstico da realidade em que se insere a unidade escolar.

O PPP nasce de uma intencionalidade declarada, isto é, nasce com um propósito que é assumir uma ou mais categoria de análise, capaz(es) de favorecer a compreensão sobre a realidade; não é espontânea no sentido ingênuo do termo, embora possa (e até deva) acontecer respeitando o ritmo mais ou menos certo de seu lugar de origem, a instituição.

Ao se organizar, o PPP configura a identidade da unidade escolar, valendo-se para isso de instrumentos para diagnósticos interno e externo da comunidade.

Ao se desencadear, não apenas ao final, mas durante o processo de sua feitura, o PPP vai se apresentando não só como documento-referência, mas também como experiência concreta para a ação da escola.

A elaboração do PPP da instituição questiona as bases da ação administrativa, docente e discente e culmina por exigir uma nova atitude escolar em todos os níveis da instituição, desde as estruturas relativas ao gerenciamento maior até, e principalmente, a organização do trabalho de sala de aula.

Esse processo gradativo e natural que se organiza vai, também, pouco a pouco descortinando a necessidade da indissociabilidade teoria/prática, num exercício propiciatório à reflexão crítica e que visa a comprometer todos os sujeitos sociais com os problemas da Educação e, por extensão, da comunidade.

Ao mesmo tempo, o clima democrático que se faz necessário instalar, acelera o processo participativo que, dialeticamente, alimenta a experiência de cidadania, fundamentais para superar o espírito individualista e autoritário presente na sociedade e em muitas instituições escolares. (FERREIRA, 2008, p. 33).

Esses aspectos norteadores para a organização do Projeto Político Pedagógico são imprescindíveis para organizar o trabalho pedagógico. É de suma importância que todos estejam envolvidos e façam o diagnóstico da realidade para resolução das problemáticas do cotidiano escolar, de modo que o documento seja utilizado para a concretização dos objetivos, 
da intencionalidade pretendida e não se configure apenas como um documento construído para cumprimento e encaminhamento às autoridades educacionais. O projeto deve ser elaborado com significação, com compromisso, luta, objetivos e metas traçadas, visando, sempre, uma transformação. Por isso, sustentamos, assim como Ferreira (2008, p. 51), que "um projeto é sempre um empreendimento, organização de ações em função de necessidades e desejos de sujeitos concretos. É sempre o anúncio de algo que se quer alcançar”.

Essa mudança exige organização e luta constante dos atores envolvidos, principalmente dos gestores, diretor e coordenador pedagógico, particularmente, do coordenador, o qual é responsável por liderar esse trabalho pedagógico, planejando as ações com vistas à participação de todos. Assim sendo, “os responsáveis pela administração escolar devem despertar em todos os integrantes da escola, educadores, pais, alunos e comunidade, o desejo de participar" (LIMA, 2007, p. 67). É com essa participação que devemos refletir sobre o que funciona e o que não funciona, objetivando posteriores mudanças, "construir de novo ou reconstruir sobre o velho", como assegura Imbernón (2009, p. 18).

Portanto, o que precisa ser entendido é que o processo de formação da subjetividade humana expressa um projeto de civilidade, por isso é que no âmbito da organização do trabalho educativo na escola, para melhorar a qualidade da formação pedagógica, é essencial olhar com cuidado e atenção para "a concepção de educação que orienta o discurso e a prática dos professores que formam professores" (PARO, 2011, p. 157), bem como ouvir a voz que expressa os desejos e necessidades formativas dos professores.

Em meio a tantas dificuldades encontradas no cotidiano escolar é que nos inquietamos e buscamos alternativas para a organização do trabalho pedagógico. Nessa direção, recorremos à formação continuada, a qual "deve aproximar-se à escola e partir das situações problemáticas dos professores" (IMBERNÓN, 2009, p. 35), sendo primordial que a formação parta da realidade em que se encontram, porque, caso a formação ocorra de forma descontextualizada, fragmentada e distante dos problemas da cotidianidade, não será possível a organização do trabalho pedagógico para posteriores inovações na prática docente. A ordenação do projeto da escola, mediado pelo diálogo problematizador, é que constitui o caminho para a formação, pois é neste espaço que cada agente educativo passa a ser reconhecido como sujeito de sua prática, assim como a escola passa a ser compreendida como espaço para ensinar, aprender e construir conhecimento. A constituição do projeto político pedagógico "sintetiza o desenvolvimento do exercício do diálogo para instauração do processo democrático e formação" permanente de educadores centrada na escola (CARVALHO, 2006, p. 183). 
Contudo, sublinhamos que uma formação deve ser planejada, pensada a partir de um projeto, a partir de dentro, centrada na escola, porque, dessa forma, possibilitará interação, reflexão sobre a prática e organização coletiva de forma democrática, pois, conforme Carvalho (2006),

\begin{abstract}
A formação contínua na escola obedece à lógica da constituição do projeto educativo, onde a formação docente se articula com o projeto de gestão da escola que toma como ponto de partida, do processo de formação, a própria experiência dos professores na perspectiva de refletir sobre a prática, buscando produzir novos conhecimentos a partir da interação recíproca no contexto escolar. (CARVALHO, 2006, p. 181).
\end{abstract}

Logo, a formação organizada através de um projeto coletivo, de forma crítica, autônoma e com reflexão sobre a prática resultará num compromisso de mudanças nas ações dos envolvidos no cotidiano escolar. Por isso, assumimos, como Imbernón (2009, p. 42), que "a formação por si só consegue muito pouco se não estiver aliada a mudanças do contexto, da organização, de gestão e de relações de poder entre os professores". Assim sendo, uma formação deve ser intencional e organizada para que seja efetivada com qualidade.

Sobre essa questão, Imbernón (2009) esclarece que é importante:

- A reflexão sobre a prática num contexto determinado;

- a criação de redes de inovação, comunidades de prática, formativas e comunicação entre o professorado;

- a possibilidade de uma maior autonomia na formação com a intervenção direta do professorado;

- partir dos projetos das escolas para que o professorado decida qual a formação de que necessita para levar adiante o desenho, a colocação em prática e a avaliação do projeto; e

- sobretudo, como idéia-eixo, mais do que ter a intenção de 'atualizá-los' potencializar uma formação que seja capaz de estabelecer espaços de reflexão e participação para que 'aprendam' (mais aprendizagem do ensino na formação) com a reflexão e a análise das situações problemáticas dos centros e que partam das necessidades democráticas (sentidas) do coletivo para estabelecer um novo processo formativo que possibilite o estudo da vida na aula e no centro, os projetos de mudança, o trabalho colaborativo como desenvolvimento fundamental da instituição educativa e do professorado. (IMBERNÓN, 2009, p. 39, grifo do autor).

Vale ressaltar que é fundamental que a formação continuada aconteça no espaço da escola, pois compreendemos que "é lá o lugar onde o professor organiza e exercita sua prática, num contexto dinâmico que possibilita o exercício de uma reflexão orientada pela própria prática pedagógica.” (DOMINGUES, 2014, p. 65). O espaço escolar é o lugar ideal para a formação continuada porque possibilita reflexão sobre a prática, e, nesse processo formativo, as coisas devem acontecer de maneira crítica e organizada, sob a liderança do coordenador pedagógico, que desempenha um papel essencial na articulação da formação e na organização da participação de todos os envolvidos, de acordo com as experiências, as práticas no contexto escolar e o projeto político pedagógico que referencia a formação centrada na escola. 
A formação na escola, assegura Domingues (2014),

[...] tem como características a valorização dos conhecimentos produzidos pelos professores na prática pedagógica diária e a interação entre os professores e o coordenador pedagógico. Isso não significa valorar todas as práticas docentes na escola, mas construir uma reflexão crítica sobre elas, de modo que os professores desvelem as teorias por trás de seus saberes e fazeres. (DOMINGUES, 2014, p. 83).

Essa interação entre coordenador pedagógico e professores, no processo formativo, possibilita o desenvolvimento da organização do trabalho pedagógico e caminhos para uma escola melhor para todos. Dessa forma, entendemos, como Imbernón (2009, p. 62), que é importante "aprender num ambiente de colaboração, de diálogo profissional e de interação social: compartilhar problemas, fracassos e êxitos. Criar um clima de escuta ativa e de comunicação." Por isso, é fundamental ter compromisso com a organização do trabalho pedagógico e assumir os desafios para que haja inovação na prática educativa.

Contudo, vemos como relevante, e também, necessário, "refletir sobre uma outra maneira de pensar a organização escolar, a cultura, o relacionamento entre as pessoas e, principalmente, a prática desenvolvida no espaço escolar.” (LIMA, 2007, p. 117). Nesse sentido, para que haja mudança, transformação, inovação, todos os envolvidos no processo educativo devem participar, de modo coletivo e democrático, de toda organização do trabalho escolar. Entendemos, então, que a formação continuada na escola seja o instrumento imprescindível para a organização do trabalho pedagógico na perspectiva de uma formação de sujeitos humanizados, críticos, criativos, curiosos e conscientes de seu papel, de sua responsabilidade e compromisso com o processo educativo.

No que tange à organização do trabalho pedagógico na escola, precisamos da gestão comprometida com o trabalho coletivo que potencializa a importância da prática docente construtiva enquanto espaço de produção de conhecimento e formação do professor. Sobre essa questão, vejamos o que disse Paulo Freire (1997, p. 68): “somos, porém, os únicos seres capazes de poder ser objetos e sujeitos das relações que travamos como os outros e com a história que fazemos e nos faz e refaz".

Nessa perspectiva, é possível inferir que a formação permanente centrada na escola constitui-se como exigência que qualifica a educação pública na contemporaneidade.

Porque a formação de professores é indissociável de um projeto de governação de escola que se fundamenta numa concepção de educação, ser humano, sociedade e formação. Refletir sobre a formação e organização do trabalho pedagógico na escola requer entender que neste espaço temos "muitas culturas". E "uma sociedade multicultural deve educar o ser humano multicultural, capaz de ouvir, de prestar atenção ao diferente, de respeitá-lo" (GADOTTI, 2000, 
p. 117). Aqui se justifica a importância de um projeto de formação centrado na escola, enquanto instrumento de mediação para o desenvolvimento profissional.

\section{Considerações finais}

Considerando que a formação é exigência e resultado da condição do inacabamento do ser humano, bem como da consciência desse inacabamento, entendemos que esse pressuposto legitima a formação permanente centrada na escola, sobretudo porque no decorrer do exercício profissional, os professores encontram-se em situações complexas, que precisam de respostas teórico-metodológicas para melhor qualificar o processo de ensino e aprendizagem. Assim, no cotidiano da escola faz-se necessário produzir novas reflexões sobre fins e pressupostos filosóficos que devem orientar a formação do ser humano.

Embora não se trate de uma conclusão fechada, é necessário considerar a formação centrada na escola como centralidade para a organização do trabalho pedagógico, tendo em vista que a formação pensada nesse espaço da escola, a partir de dentro, possibilita que os envolvidos no processo educativo possam refletir sobre sua prática. São as suas reflexões, suas problemáticas cotidianas que desencadeiam mudanças, alternativas para a organização do trabalho pedagógico com a intenção de intervir nas ações pedagógicas.

Assim, constatamos a importância da reflexão, discussão, debates e conflitos coletivos na formação continuada. Julgamos que é a partir da realidade, do contexto, planejamento e avaliação que podemos buscar a qualidade da educação pretendida. Torna-se necessário, por conseguinte, que os envolvidos construam o seu projeto de formação de forma dialógica e definam de forma clara os objetivos que pretendem atingir com a formação continuada na escola para que, de fato, venham a acontecer as mudanças na prática pedagógica. Coadunamos, portanto, com a ideia de Imbernón (2009, p. 39, grifo do autor) de que é importante "potencializar uma formação que seja capaz de estabelecer espaços de reflexão e participação para que 'aprendam' (mais aprendizagem do que ensino na formação) com reflexão e a análise das situações problemáticas dos centros".

Isso posto, é imprescindível a construção de um projeto de formação articulado com o projeto político pedagógico elaborado na coletividade e que parta das problemáticas do cotidiano, visando inovação e mudança nas práticas.

Dessa forma, refletindo sobre a formação centrada na escola, podemos concluir que é fundamental que os atores envolvidos no processo educativo (re)pensem coletivamente sobre a 
própria prática, no intuito de garantir um trabalho pedagógico inovador e transformador da realidade educativa.

A formação centrada na escola tem implicação com a formação permanente de professores, no sentido de compreender que a escola está inserida num tempo histórico, interconectada por determinações políticas. Dessa maneira, a organização do trabalho pedagógico não está dissociada da concepção que o professor tem sobre educação, conhecimento, mundo, ser humano, por isso, o desenvolvimento da educação de qualidade social requer a formação permanente dos professores para que possam melhor pensar, organizar e planejar a prática.

Ao longo desta reflexão, enfatizamos que, na escola, a forma da gestão e de como se organiza o trabalho pedagógico torna-se referência, podendo até constituir-se como instrumento mobilizador no contexto social que influencia no processo de organização da subjetividade e concepção social do sujeito na escola, de tal forma que consideramos a formação centrada na escola como instrumento de mediação fundamental de estudo, investigação e reflexão da prática.

A educação de qualidade social requer que o professor tenha liberdade para organização de um trabalho pedagógico comprometido com a formação do sujeito coletivo, capaz de compreender o mundo do trabalho e posicionar-se criticamente na realidade em que está inserido. A formação centrada na escola parte do pressuposto que "o professor se faz no processo, a sua formação é permanente, na prática e na reflexão sobre a prática” (CARVALHO, 2005, p. 64), para desvelar as determinações sociais que subjazem na realidade em que atua.

Assim, para a docência de melhor qualidade, é condição básica que o professor assuma a formação e autoformação como parte indissociável da natureza de sua profissão. Nessa perspectiva, ressaltamos que a formação docente centrada na escola, configura-se como mediação para a organização do trabalho pedagógico, bem como instrumento que impulsiona o professor a assumir uma práxis pedagógica que possa contribuir com o desvelamento da contradição da realidade social. 


\section{Referências}

CARVALHO, Ademar de Lima. Os caminhos perversos da educação: a luta pela apropriação do conhecimento cotidiano da sala de aula. Cuiabá, MT: EdUfmt, 2005.

CARVALHO, Ademar de Lima. A formação centrada na escola: a ponte edificadora do Projeto Político Pedagógico. In: MONTEIRO, Filomena Maria de Arruda; MÜLLER, Maria Lúcia Rodrigues (org.). Profissionais da educação: políticas, formação e pesquisa. ANPED, Centro-Oeste. Cuiabá: EdUfmt, 2006. p. 179-191.

CARVALHO, Ademar de Lima. A qualidade na educação: uma exigência possível. Campo Grande, MS, Série-Estudos, n. 29, jan./jun. 2010. p. 19-28.

BRANDÃO, Carlos Rodrigues. Prefácio: novas ideias sobre antigos sonhos. In: FREITAS, Ana Lúcia Souza de. Leituras de Paulo Freire: uma trilogia de referência. Passo Fundo, RS: Méritos, 2014, p. 13-22.

DOMINGUES, Isaneide. O coordenador pedagógico e a formação contínua do docente na escola. São Paulo: Cortez, 2014.

DUARTE, Newton. Arte, conhecimento e paixão na formação humana: sete ensaios de pedagogia histórico-crítica. Campinas, SP: Autores Associados, 2010.

FERREIRA, Naura Syria Carapeto. Gestão educacional e organização do trabalho pedagógico. Curitiba, PR: IESDE Brasil S.A., 2008.

FRANCO, Maria Amélia do Rosário Santoro. Pedagogia como Ciência da educação. 2. ed. rev. ampl. São Paulo: Cortez, 2008.

FREIRE, Paulo. A educação na cidade. São Paulo: Cortez, 1991.

FREIRE, Paulo. Professora sim, tia não: cartas a quem ousa ensinar. São Paulo: Editora Olho d'Água, 1997.

FREIRE, Paulo. Política e educação: ensaios. 5. ed. São Paulo: Cortez, 2001.

FREIRE, Paulo. Medo e ousadia: o cotidiano do professor. 13. ed. São Paulo: Paz e Terra, 2011.

FREIRE, Paulo. Pedagogia da autonomia: saberes necessários à prática educativa. 50. ed. Rio de Janeiro: Paz e Terra, 2015.

FREITAS, Ana Lúcia Souza de. Pedagogia da conscientização: um legado de Paulo Freire à formação de professores. 3. ed. Porto Alegre, RS: EdiPUCRS, 2004.

GADOTTI, Moacir. Uma escola, muitas culturas. In: GADOTTI, Moacir; RAMÃO, José E. (org.) Autonomia da escola: princípios e propostas. 3. ed. São Paulo: Cortez, 2000, p.117131. 
GADOTTI, Moacir. A escola e o professor: Paulo Freire e a paixão de ensinar. São Paulo: Publisher Brasil, 2007.

GALLERT, Adriana Ziemer. Assumir os desafios da docência: o professor enquanto sujeito da sua ação. In: TACCA, Maria Carmen V. R. (org.). Ação formativa docente e práticas pedagógicas na escola. Campinas, SP: Editora Alínea, 2016, p. 41-57.

IMBERNÓN, Francisco. Formação permanente do professorado: novas tendências, São Paulo: Cortez, 2009.

LIMA, Márcia Regina Canhoto de. Paulo Freire e a administração escolar: a busca de um sentido. Brasília: Liber Livro Editora, 2007.

LÜCK, Heloísa. Dimensões de gestão escolar e suas competências. Curitiba, PR: Editora Positivo, 2009.

PARO, Vitor Henrique. Crítica da estrutura da escola. São Paulo: Cortez, 2011.

PIMENTA, Selma Garrido. Professor reflexivo: construindo uma crítica. In: PIMENTA, Selma Garrido; GHEDIN, Roberto. (org.). Professor reflexivo no Brasil: gênese e crítica de um conceito. São Paulo: Cortez, 2002.

VEIGA, Ilma Passos Alencastro. Projeto Político-Pedagógico da escola: uma construção possível. Campinas, SP: Papirus, 1995.

VEIGA, Ilma Passos Alencastro. As dimensões do Projeto Político Pedagógico: novos desafios para a escola. 9. ed. Campinas, SP: Papirus, 2012. 